\title{
Total skin electron irradiation techniques: a review
}

\author{
Tomasz Piotrowski ${ }^{1,2}$, Piotr Milecki ${ }^{1,3}$, Matgorzata Skórska ${ }^{2}$, Dorota Fundowicz ${ }^{4}$ \\ 1Department of Electroradiology, Poznan University of Medical Sciences, Poland \\ Head: Prof. Julian Malicki PhD \\ 2Department of Medical Physics, Greater Poland Cancer Centre, Poznan, Poland \\ Head: Prof. Julian Malicki PhD \\ ${ }^{3}$ First Radiotherapy Department, Greater Poland Cancer Centre, Poznan, Poland \\ Head: Prof. Julian Malicki PhD \\ 4Second Radiotherapy Department, Greater Poland Cancer Centre, Poznan, Poland \\ Head: Joanna Kaźmierska MD, PhD
}

\begin{abstract}
Total skin electron irradiation (TSEI) has been employed as one of the methods of mycosis fungoides treatment since the mid-twentieth century. In order to improve the effects and limit the complications following radiotherapy, a number of varieties of the TSEI method, frequently differing in the implementation mode have been developed. The paper provides a systematic review of the different varieties of TSEl. The discussed differences concerned especially: (i) technological requirements and geometric conditions, (ii) the alignment of the patient, (iii) the number of treatment fields, and (iv) dose fractionation scheme.
\end{abstract}

Key words: mycosis fungoides, radiotherapy, electron radiation, total skin electron irradiation, review of irradiation techniques.

\section{Introduction}

The most prevalent entity in the group of primary cutaneous lymphomas is mycosis fungoides (MF), epidermotropic CTCL (cutaneous T-cell lymphoma), which is characterised by the proliferation of small and medium T-cells with cerebriform nuclei [1, 2]. The first description of the disease was provided by Alibert in 1806 and 70 years later Bazin identified its 3 classic stages: patch phase, which was initially called the pre-tumour period, plaque phase, and tumour phase [1-6]. Mycosis fungoides presents more often in men than in women. The disease concerns mainly adult population as only isolated cases have been diagnosed in children [7-9].

The choice of the treatment method depends primarily on the stage of the disease. Nonetheless, factors such as age and condition of the patient, the effects of earlier treatments and the therapeutic opportunities offered by the medical centre undertaking the treatment also have to be taken into consideration [9-11]. Mycosis fungoides treatment resorts to a number of methods in various modifications. The cases limited to skin surface are treated with corticosteroid ointments, topical chemotherapy with chlormethine or carmustine, photochemotherapy (psoralen + UVA, PUVA) or UVB phototherapy, and radiotherapy with total skin electron irradiation [12-20]. Each of the above mentioned methods may be combined with immunotherapy or retinoids [21-27]. Chemotherapy is used mainly as a form of palliative treatment of the cases at an advanced stage with lymph nodes or visceral organs affected as well as in the case of relapses as a salvage treatment $[8,10,11,28,29]$.

Total skin electron irradiation (TSEI) was introduced to the treatment of mycosis fungoides in the 1950s [30, 31]. Total skin electron irradiation can assume various forms but it needs to be pointed out that all of them should lead to complete or partial remission and at the same time be characterised by low toxicity. The condition necessary to reach adopted goals is obtaining a uniform dose for the entire irradiation target volume (construed as epidermis, adnexal structures and dermis [32]). Moreover, it is desirable to provide maximum comfort for the patient during the procedure.

Address for correspondence: Tomasz Piotrowski PhD, Greater Poland Cancer Centre, Department of Medical Physics, 15 Garbary Str. 61-866 Poznan, Poland, phone: +48 6188507 63, fax: +48 6188505 51, e-mail: tomasz.piotrowski@me.com Received: 18.09.2012, accepted: 14.01.2013. 
The present paper provides a systematic review of TSEI techniques basing on the guidelines set as a result of the consensus reached by the European Organization for Research and Treatment of Cancer (EORTC) concerning radiotherapy in the management of mycosis fungoides [33]. Special emphasis was laid on the differences in the way of treatment implementation and obtained dose distributions. Analysing the mode of treatment implementation the following issues are described: (i) technological requirements and geometric conditions of the method, (ii) the alignment of the patient, (iii) the number of treatment fields, and (iv) dose fractionation scheme.

\section{Guidelines for total skin electron irradiation}

According to the EORTC recommendations [33], nonhomogeneity of dose distribution in the air in the treatment plane should not exceed $\pm 10 \%$. The total photon contamination in electron beam ought not to exceed 0.7 Gy. The distance between the source and the patient should remain within the range of $3 \mathrm{~m}$ to $8 \mathrm{~m}$.

The dose administered to the skin surface in the process of TSEl radiotherapy method should amount to values ranging from 31 Gy do 40 Gy [33]. The total radiotherapy treatment duration depending on the dose prescribed typically lasts from 6 to 9 weeks - irradiation delivered four times per week in fractions of 1.0 Gy to 2.0 Gy with intervals on Wednesdays, Saturdays, and Sundays. The depth at which $80 \%$ of the administered dose is absorbed should be not less than $4 \mathrm{~mm}$. At the depth of $20 \mathrm{~mm}$ the absorbed dose value is not supposed to exceed $20 \%$ of the administered dose. Nominal energy of electron radiation used during electron radiotherapy should range from $4 \mathrm{MeV}$ to $8 \mathrm{MeV}$ [34-41].

In the course of electron radiotherapy by the TSEI method the patient should be positioned in such a way as to receive irradiation to the maximum area of skin surface. The majority of TSEI methods assume vertical positioning of the patient, thus it is necessary to supplement the soles of feet with additional treatment fields (sole-of-foot fields) [32-48]. The dose prescribed to sole-of-foot fields is typically 26 Gy-28 Gy. In addition, the skin areas that receive doses lower than $80 \%$ of those prescribed during electron treatment should also be supplemented with additional irradiation [31, 49-51]. Radiation energy for boost fields is prescribed depending on the depth of skin infiltration. In the case of skin lesions, radiation energy for boost fields ought to range from $3 \mathrm{MeV}$ to $6 \mathrm{MeV}$. When lymph nodes are affected, the prescribed energy depends on the depth and the location of the node (typically from $6 \mathrm{MeV}$ to 12 $\mathrm{MeV}$ ) [30-32, 52-55]. For patients with stage IVA or stage IVB disease (visceral organs involvement), additional photon radiotherapy of the entire body should be taken into consideration [56].

\section{Total skin electron irradiation techniques}

The three principal TSEI methods, which fulfil the EORTC recommendations, are: (i) large electron field techniques, (ii) rotational techniques, and (iii) techniques involving patient's shift during irradiation.

In the case of large electron field techniques, the patient is treated with irradiation while standing. In order to deliver the treatment dose, the position of the patient is changed six times during one treatment fraction starting with the anterior position, when the patient is standing facing the electron accelerator gantry, followed by the front-lateral position at the right side, back-lateral position at the left side, posterior position, back-lateral position at the right side, and finally front-lateral position at the left side. Treatment positions change every $60^{\circ}$ about the patient's longitudinal axis. The right or left orientation of the treatment position is determined by the patient's raised hand. Figure 1 presents treatment positions used in large electron field techniques [57].

If it is possible to obtain the source to skin distance (SSD) of about $7 \mathrm{~m}$ in the treatment room, the accelerator gantry is placed at the horizontal axis (the radiation beam axis is perpendicular to the patient's longitudinal axis) and each treatment position corresponds to a single treatment field. The SSD of seven metres provides treatment field size which encompasses the entire patient body surface (square fields with the side of $2 \mathrm{~m}$ or more) [30]. However, in the majority of cases, the size of the treatment room does not guarantee the possibility of obtaining such long source-to-skin distances. On average, the maximum SSD, which can be obtained, is 3-4 m. Therefore, the maximum treatment fields (a square field with the side of $1.05 \mathrm{~m}$ for SSD of $3 \mathrm{~m}$ and a square field with the side of $1.40 \mathrm{~m}$ for SSD of $4 \mathrm{~m}$ ) do not encompass the entire patient body surface. In such a situation, the solution is provided by the Stanford technique proposed by Karzmark et al. [32] which combines two treatment fields in order to deliver
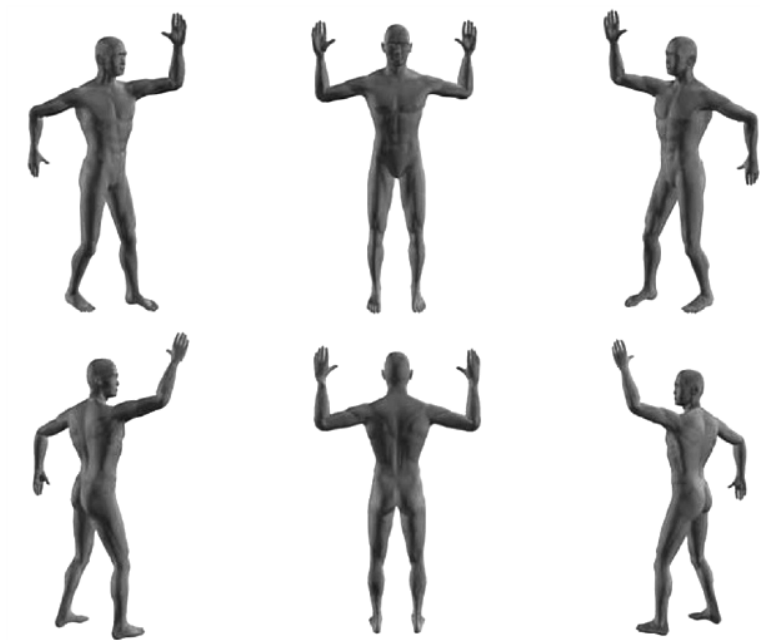

Figure 1. Treatment positions assumed during large-field TSEI [57] 


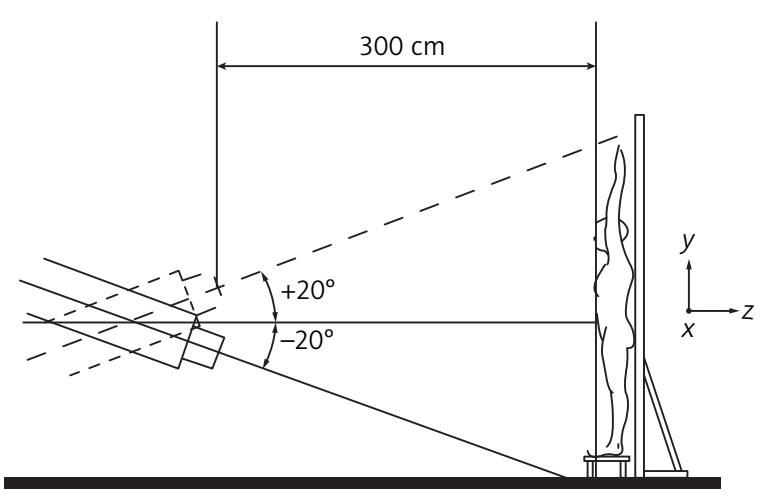

Figure 2. Positions of treatment apparatus gantry used to generate a dual field for the anterior body position in large-field TSEI [30]

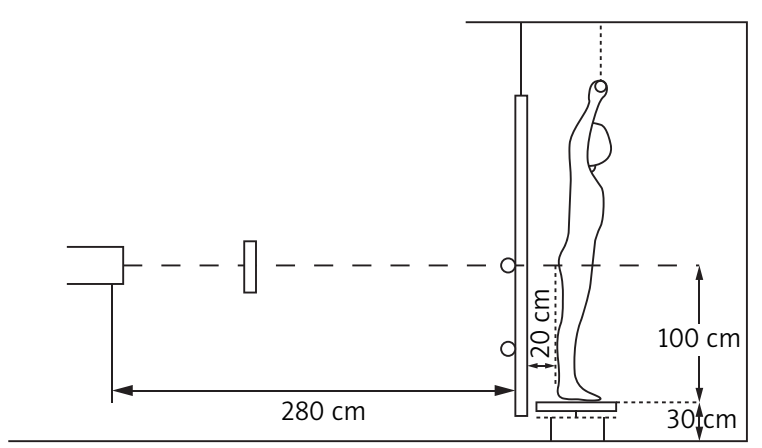

Figure 3. Patient setup and geometric conditions of the single field rotation technique [58]

dose rates to each of the six treatment positions. The overlapping of two treatment fields, which is known as a dual field, is obtained by rotating the linear accelerator about an axis, which is perpendicular to the patient skin surface. For each subfield (a composite of the dual field) the gantry rotates by the same number of degrees but in opposite directions. With SSD of $3 \mathrm{~m}$ it is possible to obtain the dual field by using two fields for which the gantry is located $20^{\circ}$ and $-20^{\circ}$ in relation to the axis, which is perpendicular to the patient plane. Figure 2 presents the positions of the treatment apparatus gantry used to produce the dual field for the anterior position during large-field TSEI [30].

In both forms of the large electron field technique discussed earlier, skin surface is irradiated in a discontinuous manner - six treatment positions are used. Therefore, it is of paramount importance to deliver a uniform dose across and along the patient's longitudinal axis. This guarantees the comparability (to an accuracy of 10\%) of the doses absorbed in the skin of hands, forearms, head and lower limbs (the parts of patient's body located outside the central part of a treatment field) with the doses absorbed in the skin of the trunk (the area of patient's body located in the centre of a treatment field). In order to improve dose homogeneity, special scatters are fitted directly in the gantry of the treatment machine. It should be noted, however, that in the case of techniques based on dual fields, scattering filters are used solely to increase dose homogeneity across the longitudinal axis of the body since dose homogeneity along the body's longitudinal axis is acceptable.

Continuous skin irradiation is carried out using rotational techniques. There are two main varieties of this technique: classic [58-60] and rotary-dual.

In the classic rotational technique, the patient is placed on a rotation platform and one field is used in the process of irradiation (the gantry of medical accelerator is positioned along the horizontal axis).

In the process of irradiation, the patient is automatically rotated at a constant speed about the vertical axis of the body. Similarly to a single field technique of large electron fields, it is necessary to use large SSDs ( 7 $\mathrm{m})$ so that the treatment field of an adequate size covering patient's entire body can be produced. Moreover, it is essential to use scatters ensuring uniform dose distribution along the longitudinal axis of the patient. Dose homogeneity across the patient, on the other hand, is compensated by constant rotation during irradiation. Podgorsak [58] used a modified scattering filter, which not only ensures appropriate dose homogeneity along the longitudinal axis of the body but also significantly scatters electron radiation and thus enlarges the treatment area. Hence, the SSD can be reduced from $7 \mathrm{~m}$ to $3 \mathrm{~m}$. The size of the treatment field produced in the patient plane at the $3 \mathrm{~m} \mathrm{SSD} \mathrm{for} \mathrm{this}$ technique is $2.5 \mathrm{~m} \times 2.5 \mathrm{~m}$. Figure 3 illustrates the patient setup and geometric conditions of the single field rotation technique.

An alternative for the technique proposed by Podgorsak et al. is rotary-dual technique developed at the Greater Poland Cancer Centre [39, 40]. Irradiation, in the course of which the patient is rotated about his/her vertical axis, is delivered using one dual field. Like in the Stanford technique, a dual field offers the possibility of a significant reduction of SSD (up to $3 \mathrm{~m}$ ) without the use of the scattering filter, which is indispensible in the classic rotational technique. Furthermore, as in the classic rotational technique, the rotational movement of the patient in the course of irradiation eliminates the necessity to apply scatters, which improve dose homogeneity across the patient's body. Figure 4 shows patient setup and geometric conditions of the rotary-dual technique.

Both large electron fields and rotational techniques involve the standing position of the patient in the course of irradiation. On the other hand, the third group of TSEI techniques involves different positioning of the patient. In this case the patient is placed on a specially modified treatment table, which moves along the longitudinal axis of the body [61]. The technique adopted in the Christie Hospital of Manchester [62] is a case in point here. One form of this method, which dispenses with continuous patient shift, is the technique adopted in the Northern Israel Oncology 
Centre [49] involving patient irradiation with four or five sets of fields, each requiring a separate positioning. In the process of irradiation with each set of fields, the patient remains stationary and is moved along during setup alteration. In the case of both these techniques, it was possible to obtain SSD of ca. $1.5 \mathrm{~m}$. In order to increase SSD to 2-2.5 $\mathrm{m}$ and, what follows increase treatment field size $\mathrm{Wu}$ et al. [63] dispensed with the treatment table and placed the patient on the floor. The patient is irradiated with dual fields for six horizontal positions corresponding to positions used in the large electron field technique (Figure 1).

In the case of all the techniques presented above, the energy of ionizing radiation, which is mainly applied, is the nominal energy of $6 \mathrm{MeV}$ which on skin surface produces for the SSD of 3 m electron radiation of mean energy equal to $2.5 \mathrm{MeV}$.

\section{Discussion and conclusions}

Each of the presented irradiation techniques fulfils the recommendations set by the EORTC [33]. However, while making a choice about the technique a number of factors crucial to its implementation should be considered. These factors include: (i) irradiation time, (ii) total fraction time, (iii) the size of the radiotherapy treatment room, (iv) patient's comfort, and (v) the number of local boost fields, for which the dose delivered in the process of total skin irradiation is smaller than $80 \%$ of the prescribed dose.

The majority of medical accelerators are equipped with a special treatment protocol which allows for TSEI delivery. Unlike classic protocols it offers the possibility of electron radiation of high dose rate expressed as the number of monitor units emitted by the medical accelerator per minute (JM/min). In the case of TSEl it is $900 \mathrm{JM} / \mathrm{min}$ and in the case of classic treatment protocols it amounts to $300 \mathrm{JM} / \mathrm{min}$. When a medical accelerator is adjusted so that one monitor unit represents one centigrey (cGy), the dose rate for TSEl protocol is $9 \mathrm{~Gy} / \mathrm{min}$ and is three times the size of the dose rate for classic protocols $-3 \mathrm{~Gy} / \mathrm{min}$. However, it should be noted that these calculations are carried out for standard conditions assuming dose measurement at SSD of 100 $\mathrm{cm}$ used in the case of classic treatment protocols. Taking into account both SSD applied in TSEI which varies from 3 $\mathrm{m}$ to $7 \mathrm{~m}$ and the law which says that the dose rate decreases as the square of the distance [64], the dose rate for TSEI depending on SSD is $1 \mathrm{~Gy} / \mathrm{min}$ for SSD of $3 \mathrm{~m}$ and $0.2 \mathrm{~Gy} / \mathrm{min}$ for SSD of $7 \mathrm{~m}$. It is worth emphasising that in the case of treatments using 3-metre SSD the number of fields necessary to deliver a treatment dose twice exceeds (dual fields) the number of fields used in treatments carried out at $7 \mathrm{~m}$ SSD. To conclude, the duration time necessary to deliver treatment dose for irradiation techniques employing SSD $3 \mathrm{~m}$ is two and a half times shorter than for techniques using SSD of $7 \mathrm{~m}$. The issues presented concern the irradiation time, which is only one of the two composites of total time of irradiation fraction delivery. The time, which should be

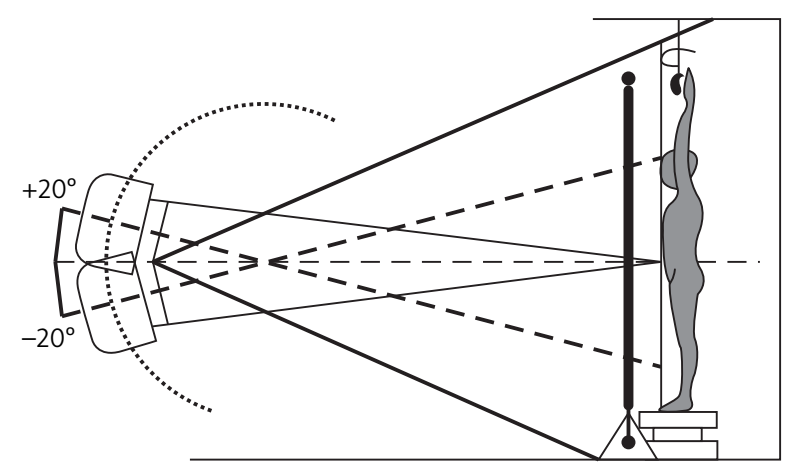

Figure 4. Patient setup and geometric conditions of the rotary-dual technique [40]

devoted to the appropriate positioning of the patient before the start of the irradiation process, also plays an important role. The review of TSEI techniques conducted by Diamantopoulos et al. [65] proved that the Stanford technique is the most time-consuming as far as positioning is concerned while the rotational technique requires the least amount of time. This results from the need to repeat six times the procedures of patient setup (the procedure is repeated separately for each treatment position) while only 1 patient position is required for the rotational technique.

In the last 10 years, dual techniques have completely supplanted single-field techniques which use large SSDs. This results mainly from the following factors: (a) a considerable reduction of irradiation time for the techniques carried out at SSD of $3 \mathrm{~m}$; (b) no need to position dual fields twice, and (c) the fact that 7-metre distances between the source of irradiation and patient's skin are frequently unattainable in treatment rooms.

In the analysis the aspects relating to patient's comfort in the course of irradiation, both absence of differences between rotational and the Stanford techniques and a significant increase in patient's comfort for techniques involving the horizontal position of a patient should be emphasised.

All irradiation techniques require application of local boost fields for which the dose delivered is smaller than $80 \%$ of the prescribed dose. In the case of techniques involving irradiation of the patient in the sitting position, the areas typically requiring boosting are the soles of feet, vertex of the head, perineum and medial thighs. The number of boost fields differs slightly depending on the technique with the rotational technique requiring more boosts than the Stanford technique.

Finally, in order to verify dose distribution, the in vivo dosimetry method should be applied. The reports presenting the results of dosimetric measurements confirm that uniformity of dose distribution varies from $90 \%$ to $110 \%$ of the planned dose for all the techniques discussed in the present paper [44, 50, 51, 66-76]. 


\section{Acknowledgments}

The authors would like to express special thanks to Joanna Kaźmierska, Head of the Second Radiotherapy Department in the Greater Poland Cancer Centre, for her insightful comments on this article.

\section{References}

1. Willemze R, Kerl H, Sterry W, et al. EORTC classification for primary cutaneous lymphomas. A proposal from the Cutaneous Lymphoma Study Group of the European Organization for Research and Treatment of Cancer (EORTC). Blood 1997; 90: 354-71.

2. Willemze R, Meijer C. EORTC Classification for primary cutaneous lymphomas: the best guide to good clinical management. Am J Dermatopathol 1999; 21: 265-73.

3. Alibert JLM. Tableau de plan fongoide: Description des maladiesde la peauobserveeal 'hopital St. Louis, et exposition des meilleures methods suivies pour leurtraitment. Paris, France, Bariorl'Aineet Files 1806.

4. Willemze R. Primary cutaneous lymphomas. Curr Opin Oncol 2000; 12: 419-25.

5. Grzanka A, Placek W. Modern diagnostic methods in cutaneous T-cell limphomas. Postep Derm Alergol 2004; 21: 220-5.

6. Goździcka-Józefiak A, Poręba E, Bręborowicz J, et al. The use of immunohistochemistry and molecular biology techniques in the diagnosis of mycosis fungoides. Postep Derm Alergol 2003; 20: 73-9

7. Bao Q, Hrycushko BA, Dugas JP, et al. A technique for pediatric total skin electron irradiation. Radiat Oncol 2012; 7: 40.

8. Fung MA, Murphy MJ, Hoss DM, et al. Practical evaluation and management of cutaneous lymphoma. J Am Acad Dermatol 2002; 46: 325-57.

9. Lanier C, Andre V, Seguin V, et al. Recurrence of Stachybotrys chartarum during mycological and toxicological study of bioaerosols collected in a dairy cattle shed. Ann Agric Environ Med 2012; 19: 61-7.

10. Freiman A, Sasseville D. Treatment of mycosis fungoides: overview. J Cutan Med Surg 2006; 10: 228-33.

11. Trautinger F, Knobler R, Willemze R, et al. EORTC consensus recommendations for the treatment of mycosis fungoides/Sézary syndrome. Eur J Cancer 2006; 42: 1014-30.

12. Ramsay DL, Halperin PS, Zeleniuch-Jacquotte A. Topical mechlorethamine therapy for early stage mycosis fungoides. J Am Acad Dermatol 1989; 10: 684-91.

13. Zackheim HS, Epstein EH, Crain WR. Topical carmustine (BCNU) for cutaneous T cell lymphoma: a 15-year experience in 143 patients. J Am Acad Dermatol 1990; 22: 802-10.

14. Ramsay DL, Lish KM, Yalowitz CB, et al. Ultraviolet-B phototherapy for early stage cutaneous T-cell lymphoma. Arch Dermatol 1992; 128: 931-3.

15. Resnick KS, Vonderheid EC. Home UV phototherapy of early mycosis fungoides: long-term folow-up observations in thirty-one patients. J Am Acad Dermatol 1993; 79: 73-7.

16. Roenigk $\mathrm{HH}$. Photochemotherapy for mycosis fungoides. Cancer Treat Rep 1979; 63: 669-73.

17. Hoppe RT, Cox RS, Fuks Z, et al. Electron beam therapy for mycosis fungoides: the Stanford University experience. Cancer Treat Rep 1979; 63: 691-700.

18. Sikorska M, Sokołowska-Wojdyło M, Kowalczyk A, Roszkiewicz J. Effectiveness of interferon alpha in mycosis fungoides therapy. Postep Derm Alergol 2012; 29: 51-5.
19. Olek-Hrab K, Osmola-Mańkowska A, Silny W, et al. Use of UVA1 in the treatment of mycosis fungoides - case report. Postep Derm Alergol 2011; 28: 158-64.

20. Jenerowicz D, Silny W, Dańczak-Pazdrowska A, et al. Environmental factors and allergic diseases. Ann Agric Environ Med 2012; 19: 475-81.

21. Roenigk HH, Kuzel TM, Skoutelis AP, et al. Photochemotherapy alone or combined with interferon alpha-2a in treatment of cutaneous T-cell lymphoma. J Invest Dermatol 1990; 95: 188-205.

22. Kessler JF, Jones SE, Levine N, et al. Isotretinoin and cutaneous helper T-cell lymphoma (mycosis fungoides). Arch Dermatol 1987; 123: 201-4.

23. Thomsen K, Hammar H, Molin L, et al. Retinoids plus PUVA (RePUVA) and PUVA in mycosis fungoides, plaque stage. A report from the Scandinavian Mycosis Fungoides Group. Acta Derm Venereol (Stockh) 1989; 69: 536-8.

24. Kuzel TM, Gilyon K, Springer E, et al. Interferon alfa-2a combined with phototherapy in the treatment of cutaneous T-cell lymphoma. J Natl Cancer Inst 1990; 82: 203-7.

25. Batycka-Baran A, Reich A, Jankowska-Konsur A, Maj J. New trends in the management of mycosis fungoides and Sezary syndrome. Postep Derm Alergol 2009; 26: 41-55.

26. Osmola-Mańkowska A, Silny W, Dańczak-Pazdrowska A, et al. The sun - our friend or foe? Ann Agric Environ Med 2012; 19: 805-9.

27. Śpiewak R. The substantial differences between photoallergic and phototoxic reactions. Ann Agric Environ Med 2012; 19 : 888-9.

28. Wojewoda K, Brenner J, Sokołowska-Wojdyło M, BarańskaRybak W. Treatment of primary cutaneous lymphoma with reference to the latest therapeutic consensus of the Polish Lymphoma Research Group (PLRG). Postep Derm Alergol 2012; 29: 63-8.

29. Jankowska-Konsur A, Maj J, Woźniak Z, Baran E. Angiogenesis assessment in patients with mycosis fungoides. Postep Derm Alergol 2009; 26: 186-9.

30. AAPM report no. 23. Total skin electron therapy: technique and dosimetry. New York: American Institute of Physics, 1987.

31. Jones GW, Hoppe RT, Gladstein E. Electron treatment for cutaneous T-cell lymphoma. Hemat Clin 1995; 9: 1057-76.

32. Karzmark CJ, Loevinger R, Steele RE. A technique for large-field, superficial electron therapy. Radiology 1960; 74: 633-44.

33. Jones GW, Kacinski BM, Wilson LD, et al. Total skin electron radiation in the management of mycosis fungoides: consensus of the European Organization for Research and Treatment of Cancer (EORTC) Cutaneous Lymphoma Project Group. J Am Acad Dermatol 2002; 47: 364-70.

34. Edelson R. Cutaneous T cell lymphomas-perspective. Ann Intern Med 1975; 83: 548-52.

35. ICRU Report 35. Radiation dosimetry: electron beams with energies beetwen 1 and 50 MeV. Maryland: ICRU Publ 1984.

36. Braams R. Superficial radiation therapy of large skin areas. Dermatologica 1958; 117: 204-14.

37. Meyler T, Blumberg A, Purser P. Total skin electron beam therapy. Cancer 1978; 42: 1171-6.

38. Fraass BA, Robertson PL, Glatstein E. Whole - skin electron treatment: patient skin dose distribution. Radiology 1983; 146: 811-4.

39. Pawlaczyk M, Piotrowski T, Fundowicz D, et al. Napromienianie całej skóry wiązkami elektronowymi w terapii ziarniniaka grzybiastego. Przegl Dermatol 2002; 89: 289-95.

40. Piotrowski T, Malicki J. The rotary dual technique for total skin irradiation in the treatment of mycosis fungoides - a descrip- 
tion of applied method. Rep Pract Oncol Radiother 2006; 11: 29-37.

41. Toossi MTB, Momennezhad M, Hashemi SM. Monte Carlo simulation for Neptun 10 PC medical linear accelerator and calculations of output factor for electron beam. Rep Pract Oncol Radiother 2012; 17: 115-8.

42. Gerbi BJ, Khan FM, Deibel FC, et al. Total skin electron arc irradiation using a reclined patient position. Int J Radiat Oncol Biol Phys 1989; 17: 397-404.

43. Kumar PO, Patel IS. Rotation technique for superficial total body electron beam irradiation. J Natl Med Assoc 1978; 70: 507-9.

44. Antolak JA, Cundiff JH, Ha CS, et al. Utilization of thermoluminescentdosimetry in total skin electron beam radiotherapy of mycosis fungoides. Int J Rad Oncol Biol Phys 1998; 40: 101-8.

45. Antolak JA, Hogstrom KR. Multiple scattering theory for total skin electron beam design. Med Phys 1998; 25: 851-9.

46. el-Khatib E, Hussein S, Nikolic M, et al. Variation of electron beam uniformity with beam angulation and scatterer position for total skin irradiation with the Stanford technique. Int J Radiat Oncol Biol Phys 1995; 33: 469-74.

47. Kim TH, Pla C, Pla M, et al. Clinical aspects of a rotational total skin electron irradiation. Br J Radiol 1984; 57: 501-6.

48. van der Merwe DG. Total skin electron therapy: a technique which can be implemented on a conventional electron linear accelerator. Int J Radiat Oncol Biol Phys 1993; 27: 391-6.

49. Rosenblatt E, Kuten A, Leviov M, et al. Total skin electron irradiation in mycosis fungoides dose and fractionation considerations. Leuk Lymphoma 1998; 30: 143-51.

50. Kumar PP, Henschke UK, Nibhanupudy JR. Problems and solutions in achieving uniform dose distribution in superficial tota body electron therapy. J Natl Med Assoc 1977; 69: 645-7.

51. Desai KR, Pezner RD, Lipsett JA, et al. Total skin electron irradiation for mycosis fungoides: relationship between acute toxicities and measured dose at different anatomic sites. Int J Radiat Oncol Biol Phys 1988; 15: 641-5.

52. Wilson LD, Kacinski BM, Jones GW. Local superficial radiotherapy in the managment of minimal stage IA cutaneus T-cell lymphoma (mycosis fungoides). Int J Rad Oncol Biol Phys 1998; 40: 109-15.

53. Vloten WA, Vroome H, Noordijk EM. Total skin electron beam irradiation for cutaneus T-cell lymphoma (mycosis fungoides). Br J Dermatol 1985; 112: 697-702.

54. Trump JG, Wright KA, Evans WW, et al. High-energy electrons for the treatment of extensive superficial malignant lesions. Am J Radiol 1953; 69: 623-9.

55. Freeman CR, Suissa S, Shenouda G, et al. Clinical experience with a single field rotational total skin electron irradiation technique for cutaneous T-cell lymphoma. Radiother Oncol 1992; 24: 155-62.

56. Halberg FE, Fu KK, Weaver KA, et al. Combined total body $X$-ray irradiation and total skin electron beam radiotherapy with an improved technique for mycosis fungoides. Int I Rad Oncol Biol Phys 1989; 17: 427-32.

57. Total skin electron beam treatment patient leaflet. C.C.f.O.-N.F. Trust; 2008.

58. Podgorsak EB. Review of radiation oncology physics: a handbook for teachers and students. Vienna, Austria: I.A.E. Agency; 2003.

59. Podgorsak EB, Pla C, Pla M, et al. Physical aspects of a rotational total skin electron irradiation. Med Phys 1983; 10: 159-68.

60. Reynard EP, Evans MD, Devic S, et al. Rotational total skin electron irradiation with a linear accelerator. J Appl Clin Med Phys 2008; 9: 2793.
61. Marinello G, Jaffre F, Ślosarek K, et al. Total skin electron irradiation. Proceedings of 3rd seminar on treatment planning in radiotherapy in Poznan. Rep Pract Oncol Radiother 1998; 3 : 19-22.

62. Ulutin HC, Beyan C, Pak Y. Total skin electron beam therapy for cutaneous T-cell lymphoma: Turkish experience with translational technique. Haematologia (Budap) 2002; 32: 397-403.

63. Wu JM, Leung SW, Wang CJ, Chui CS. Lying-on position of total skin electron therapy. Int J Radiat Oncol Biol Phys 1997; 39: 521-8.

64. Sardari D, Maleki R, Samavat H, Esmaeeli A. Measurement of depth-dose of linear accelerator and simulation by use of Geant4 computer code. Rep Pract Oncol Radiother 2010; 15: 64-8.

65. Diamantopoulos S, Platoni K, Dilvoi M, et al. Clinical implementation of total skin electron beam (TSEB) therapy: a review of the relevant literature. Phys Med 2011; 27: 62-8.

66 . Horowitz YS. The theoretical and microdosimetric basis of thermoluminescence and applications to delivery. Phys Med Biol 1981; 26: 765-824.

67. HPA: A practical guide to electron dosimetry below $5 \mathrm{MeV}$ for radiotherapy purposes. Hosp Phys Assoc Rep 1975; 13: 1-18.

68. Jabbari N, Barati AH, Rahmatnezhad L. Multiple-source models for electron beams of a medical linear accelerator using BEAMDP computer code. Rep Pract Oncol Radiother 2012; 17: 211-9.

69. The Cooperative Group for PET-CT in Radiotherapy Treatment Planning. Recommendations of the Spanish Societies of Radiation Oncology (SEOR), Nuclear Medicine \& Molecular Imaging (SEMNiM), and Medical Physics (SEFM) on 18F-FDG PETCT for radiotherapy treatment planning. Rep Pract Oncol Radiother 2012; 17: 298-318.

70. Weaver RD, Gerbi BJ, Dusenbery KE. Evaluation of dose variation during total skin electron irradiation using thermoluminescent dosimeters. Int J Radiat Oncol Biol Phys 1995; 33: 475-8.

71. Thwaites DI, Malicki J. Physics and technology in ESTRO and in radiotherapy and oncology: past, present and into the $4^{\text {th }}$ dimension. Radiother Oncol 2011; 100: 327-32.

72. Piotrowski T, Fundowicz D, Pawlaczyk M, Malicki J. Thermoluminescentdosimetry in rotary dual technique of the total skin electron irradiation. Neoplasma 2003; 50: 41-6.

73. Hogstrom KR, Ewton JR, Cundiff JH, et al. Beam delivery system and dosimetry for total skin electron irradiation at MDAH. Med Phys 1984; 11: 389.

74. ICRU Report 35. Radiation dosimetry: electron beams with energies beetwen 1 and 50 MeV. Maryland: ICRU Publ 1984.

75. Crespo RH, Domeno MM, Rodríguez MJP. Biodosimetry and assessment of radiation dose. Rep Pract Oncol Radiother 2011; 16: 131-7.

76. Malicki J. The importance of accurate treatment planning, delivery, and dose verification. Rep Pract Oncol Radiother 2012; 17: 63-5. 